\title{
A SOCIEDADE PERANTE AS MUDANÇAS DO MARCO POLITICO E ELEITORAL BRASILEIRO
}

\section{Entre aprimoramento referendário e experimentalismo fraudulento}

André Ramos Tavares

Livre-docente em Direito Constitucional pela USP. Doutor e Mestre em Direito Constitucional pela PUC-SP. Pró-reitor e Professor de Pós-graduação stricto sensu da PUC-SP. Diretor da Escola Judiciária Eleitoral Nacional do TSE (2010-2012).

ÁreA do Direito: Eleitoral; Constitucional

Autor convidado

Resumo: A sociedade cada vez mais presente no processo político inicia um movimento para ocupar outros espaços próximos ou internos ao "Poder". Assim ocorre pelas constantes cobranças éticas e de eficiência da classe política. Essa postura é inovadora, pois insere o cidadão em momentos até então reservados apenas aos próprios políticos. Um dos mais ilustrativos exemplos foi a iniciativa popular da chamada Lei da Ficha Limpa. A sociedade aqui surgiu como um alvissareiro elemento na equação política cujo resultado sempre foi a máxima dos legisladores que legislam em causa própria.

Pesquisas que se confirmam até a atual quadra nos dão conta da insatisfatória confiança social sobre a situação política e alguns de seus processos. Entretanto, será a mudança do sistema
ABSTRACT: The society, more and more related to the political process, starts a movement to occupy other spaces near or inside the "Power". This happens because of the constant ethics and efficiency demands of the political class. This approach is innovative because it places the citizen in some occasions reserved, before, only for politicians themselves. One of the most illustrative examples that we've had was the popular initiative usually called the Statute "Ficha Limpa" ("Clean Records" Law). The society came here as an auspicious element in the political equation, which result has always been the legislators that legislate for themselves.

Current research confirms the unsatisfactory social trust on the political situation and some of its processes. However, will it be the change of 
eleitoral pela reforma política a panaceia de todo esse mal? Poderia ser o problema enfrentado no Brasil oriundo de nossa opção de sistema eleitoral? 0 tema tem sido enfrentado de maneira consistente ou está sendo conduzido conforme outras agendas?

A proposta aqui é confrontar uma hipotética mudança de sistema eleitoral com os males e os benefícios que compõem o cenário atual, trazendo, ao final, algumas conclusões a respeito.

Palavras-chave: Sistema eleitoral - Reforma política - Democracia - Corrupção. the electoral system by the political reform the panacea of all this evil? Could be this problem, that is faced in Brazil, a result of our electoral system choice? The issue has been addressed in a consistent way or is being conducted in accordance with other concerns?

The proposal here is to confront a hypothetical change in the electoral system with the evils and benefits that make up the current scenario, bringing to an end some conclusions about it.

KeYwords: Electoral system - Political chances Democracy - Corruption.

SumÁrio: 1. Sociedade e política - 2. 0 sistema eleitoral e a reforma política: 2.1 A democracia sem democracia; 2.2 Sistema eleitoral e corrupção - 3. 0 sistema eleitoral brasileiro: 3.1 Reforma política e sistema eleitoral: a proposta do distritão e o sistema proporcional; 3.2 Reforma para facilitar a reforma; 3.3 Outra reforma, para dificultar a reforma - 4. Conclusões - 5 . Referências bibliográficas.

\section{Sociedade e política}

Uma das benesses do avanço democrático é a ampliação da transparência, facilitando a informação e a comunicação entre sociedade e Estado. Trata-se de busca que vem sendo confrontada pelo próprio Estado brasileiro. Basta recordar, a esse propósito, a recente aprovação, no ano de 2011, da Lei de Acesso às Informações e dos diversos portais de transparência abertos nos mais variados órgãos e entidades governamentais lato sensu.

Mas essa nova relação, cada vez mais dinâmica e próxima, provoca na sociedade os anseios por um bom desempenho político, reclamando por sua responsabilidade no exercício de funções públicas e deveres políticos.

Soma-se a esses fatores o caminho que está sendo sinalizado pela mesma democracia, que faz despontar para a denominada democracia participativa, conforme classificação de C. B. Macpherson, ou ainda, como alternativa, a chamada democracia dialógica ou deliberativa. Seja por uma ou outra vertente o que se identifica é um movimento de aproximação entre a sociedade e o poder estatal (TAVARES, 2012, p. 1048).

A essa equação complexa deve também ser adicionada a baixa credibilidade da população brasileira nas instituições políticas. A título de ilustração aponto a pesquisa do Ibope, realizada em 2011, mensurando o Índice de Confiança Social (ICS) onde se destacam o Congresso Nacional e os partidos políticos, 
destaque este por ocuparem as últimas posições relativas à confiança da população brasileira.

Ao serem comparados os Índices de Confiança Social dos últimos três anos, constata-se pequena oscilação nesses números e, mesmo assim, as posições ocupadas por essas instituições são as mesmas, isto é, o Congresso Nacional classificado em penúltimo lugar e os partidos políticos em último. Na comparação com o ano de 2010 há uma leve melhora na confiança, aumentando esses índices. Esse dado talvez seja, em parte, explicado, por tratar-se de ano eleitoral com eleições para Presidente da República e vice, Deputados e Senadores, mas ainda assim o Congresso Nacional e os partidos políticos ocupam os últimos lugares, conforme revela a tabela abaixo: ${ }^{1}$

\begin{tabular}{|c|c|c|c|}
\hline & 2009 & 2010 & 2011 \\
\hline - Família & 90 & 91 & 90 \\
\hline - Amigos & 67 & 69 & 68 \\
\hline - Cidadãos do país & 59 & 60 & 60 \\
\hline - Vizinhos & 59 & 59 & 59 \\
\hline - Corpo de Bambeiros & 88 & 85 & 86 \\
\hline - Igrejas & 76 & 73 & 72 \\
\hline - Forças Armadas & 71 & 69 & 72 \\
\hline - Meios de Comunicação & 71 & 67 & 65 \\
\hline - Presidente & 66 & 69 & 60 \\
\hline - Empresas & 61 & 60 & 59 \\
\hline - Organizações civis & 61 & 61 & 59 \\
\hline - Bancos & 61 & 58 & 57 \\
\hline - Escolas Públicas & 62 & 60 & 55 \\
\hline - Polícia & 52 & 52 & 55 \\
\hline - Eleições/Sistema Eleitoral & 49 & 56 & 52 \\
\hline - Governo Federal & 53 & 59 & 52 \\
\hline - Poder judiciário/Justiça & 53 & 53 & 49 \\
\hline - Governo do seu município & 53 & 50 & 47 \\
\hline - Sindicatos & 46 & 44 & 44 \\
\hline - Sistema Público de Saúde & 49 & 47 & 41 \\
\hline - Congresso Nacional & 35 & 38 & 35 \\
\hline - Partidos Políticos & 31 & 33 & 28 \\
\hline - Geral & 60 & 60 & 58 \\
\hline
\end{tabular}

1. Tabela disponível em: [www.ibope.com.br/calandraWeb/servlet/CalandraRedirect?te $\mathrm{mp}=6 \&$ proj=PortalIBOPE $\&$ pub $=\mathrm{T} \& \mathrm{db}=\mathrm{c}$ ald $\&$ comp=pesquisa_leitura $\&$ docid $=10 \mathrm{~B}$ CD9362159152B8325791E003F379E]. Acesso em: 25.02.2012. 
Esse conjunto de fatores amplifica o debate e a fiscalização da classe política em seu exercício cotidiano. Questionamentos são sempre apresentados, colocando frequentemente em xeque as opções eleitas pelo núcleo político e democrático. Nesse campo onde tradicionalmente ocorre o fenômeno dos "legisladores em causa própria" que pode ser traduzido como uma zona onde apenas a classe política deflagra, debate, delibera e aprova suas próprias regras para alcance, desenvolvimento, permanência ou exclusão do cargo político, a sociedade também passou a exercer um peso de maneira cada vez mais presente e transformadora.

Expressões (e pressões) populares alcançaram o regramento político eleitoral, chamando a sociedade para um debate que anteriormente era dominado apenas pela classe política. Nesse novo rumo, as regras eleitorais passaram a ser assunto também da sociedade, cuja maior ilustração recente foi o encaminhamento de projeto que culminou na aprovação da LC 135, de 04.06.2010, a conhecida Lei da Ficha Limpa, fruto de iniciativa popular com expressiva adesão. Vale frisar que a participação social neste caso não se restringiu apenas a iniciativa do projeto de Lei, mas também a seguiu por todo o debate, gerando diversas manifestações populares, que acompanharam a Lei mesmo após sua edição, haja vista a pressão popular e midiática exercida diante do STF para que considerasse sua constitucionalidade.

Neste novo cenário brasileiro seria impossível não retomar os antigos debates sobre uma reforma política nacional a fim de encontrar novos caminhos para os males da crise política e ética, que não deve ignorar uma igual crise partidária e de governança, em elementos que estão intrinsecamente conectados.

O Congresso Nacional criou duas comissões, uma na Câmara dos Deputados e outra no Senado, para discutir os mais variados temas que haveriam de entrar na pauta de uma reforma política. Em paralelo, embora com menor pretensão mas não de menos importância, outro passo foi dado pelo Senado, por meio de Ato da Presidência 192, de 10.06.2010, que instituiu a Comissão de Juristas para estudos e elaboração de anteprojeto de Código Eleitoral, caso no qual também a sociedade pôde participar diretamente por meio das audiências públicas realizadas em várias capitais debatendo os principais temas da área.

\section{O SISTEMA ELEITORAL E A REFORMA POLÍTICA}

Um item recorrente nos debates e nas tentativas de reforma política é a mudança do sistema eleitoral, entendendo aqui como sistema eleitoral "o conjunto de regras que define como em uma determinada eleição o eleitor pode fazer 
suas escolhas e como os votos são contabilizados para serem transformados em mandatos (cadeiras no Legislativo ou chefia do Executivo)". Esse registro não pode ser, contudo, desvinculado de uma advertência, para alertar que "o sistema eleitoral não esgota as normas que regulam as leis eleitorais de uma democracia. Existe uma série de outros aspectos que são importantes numa eleição: quais são os eleitores aptos a votar; se o voto é obrigatório ou facultativo; os critérios para apresentação de candidatos; as normas de acesso aos meios de comunicação; os mecanismos de controle dos gastos de campanha e acesso ao fundo partidário; as normas para divulgação de pesquisas; as regras da propaganda eleitoral" (Nicolau, 2004, p. 10-11).

O Brasil já está formando uma espécie de tradição nas tentativas de reforma política. Consoante Izabelle Torres no artigo "A velha tentativa de votar a reforma política", "como na maioria das ressacas de denúncias envolvendo o Congresso, os parlamentares recomeçam esta semana o debate em torno da reforma política. Na tentativa de dirimir os efeitos da crise, diversas propostas começam a unir governo e oposição no discurso de que somente as mudanças do sistema podem acabar com a imagem negativa da Casa diante da opinião pública". 2

Embora muito se tenha discutido sobre as reformas políticas, a mudança de sistema eleitoral não era uma preocupação corrente no Brasil. Jairo Nicolau, ao mencionar a intenção de trazer para o Brasil o sistema de voto distrital, relembrou que no período pós-1985 havia propostas para a adoção desse sistema eleitoral, entretanto, pela ausência de defensores significativos no país, a tese imediatamente se esvaiu. Lembra, ainda, que durante a Constituinte de 1987 havia projeto que defendia a introdução do sistema de maioria simples para as eleições parlamentares e, embora tenha tido maior expressão neste momento, foi derrotado ainda na fase das subcomissões e sequer foi apreciado em Plenário constituinte (Nicolau, 2004, p. 18).

Mais recentemente, o cientista político Alberto Carlos Almeida, preocupado com o ímpeto de se fazer uma reforma política de maneira irresponsável, em especial, diante de matéria tão delicada como é a alteração do sistema eleitoral, escreveu o artigo "Risco de dar um passo para trás" no jornal Valor Econômico em 11.02.2011 expondo que: "A minha principal crítica a propostas dessa natureza é uma crítica tipicamente conservadora, inspirada em Edmund Burke, o grande pensador conservador que escreveu o famoso livro 'Reflexões sobre a

2. Correio Braziliense, 05.05.2009. Disponível em: [www.correiobraziliense.com.br]. Acesso em: 25.02.2012. 
Revolução em França'. O argumento conservador é muito simples. Nós, individualmente, quando cuidamos de nossa vida, tendemos a ser conservadores. Tomem-se as nossas relações pessoais e de amizade. No decorrer dos anos elas mudam, porém de maneira incremental. Nós não trocamos de um ano para o outro todo o nosso conjunto de amigos e conhecidos. Isso não é feito porque causaria uma enorme disrupção, de consequências imprevisíveis, em nossa vida. Mais ainda, caso quiséssemos voltar atrás, seria muito mais difícil do que se a mudança tivesse sido incremental.

"Como somos conservadores e prudentes quando o que está em jogo é cada um de nós, o que dizer então quando se trata de coisas que têm impacto sobre a vida de milhões de pessoas. As instituições políticas, em particular as de representação, têm um enorme impacto sobre a vida de 135 milhões de eleitores brasileiros habilitados a votar. Mexer em tais instituições é mexer com a vida de todas essas pessoas. A ideia de reformar inteiramente um sistema eleitoral, abandonando o já testado sistema proporcional e adotando o distrital (com ou sem distritão) é resultado do espírito de inovação. É resultado não de um saber coletivo e social, mas de um saber egoísta e intelectual" (Almeida, 2011, p. 20).

Simplificando espantosamente a questão, no que diz respeito ao grau de rigor científico das discussões que, em regra, circundam as propostas de reforma no plano político eleitoral, afirma: "[a]lguns intelectuais leram alguns livros e aprenderam que há países que adotam o sistema distrital. Além disso, tais intelectuais pressupõem que o sistema brasileiro funciona mal" (AlmeIDA, 2011, p. 20).

A banalização da importância de eventual reforma política, em especial, quanto ao sistema eleitoral, abala a segurança necessária para o funcionamento do próprio sistema eleitoral, isto é, se o sistema eleitoral é convocado constantemente à pauta de reformas sua estrutura passa a ser frequentemente contestada podendo ser criadas fissuras fictícias trazendo ao senso comum inverdades sobre seu funcionamento, maculando sua imagem e, por fim, abalando sua própria eficiência.

Mas além desse aspecto preocupante, é preciso ainda explorar outra faceta da questão, a dificuldade técnica em debater e encontrar a nomenclatura do real sistema eleitoral (TAVARES, 2011, p. 12-13). Domenico Fisichella (2008, p. 152) realça essa problemática: "falar genericamente de sistema proporcional, de sistema majoritário, de contraposição entre uns e outros, sem qualquer especificação ulterior", diante da enorme variedade que se pode fazer referência de sistemas eleitorais de representação proporcional. Como observa Carlos Eduardo Sell (2006, p. 89) que embora teoricamente, estes diferentes princípios de representação possam ser apresentados de forma "pura", na prática, eles estão associados a outros elementos da legislação eleitoral, dando origem aos mais 
diversos sistemas eleitorais. Seel ainda cita José Antonio Giusti Tavares que em sua obra sistemas eleitorais nas democracias contemporâneas, identifica 14 sistemas exclusivamente majoritários, 22 sistemas proporcionais e 4 tipos de sistemas mistos, chegado a um total de 38 tipos de sistemas eleitorais.

Nesse mesmo sentido, Ferdinand Hermens menciona a existência, já antes da Primeira Grande Guerra, de aproximadamente 300 variedades de sistemas eleitorais.

\subsection{A democracia sem democracia}

Robert A. Dahl, dissertando sobre como podemos determinar quais são as instituições políticas necessárias para a democracia em grande escala, aponta seis requisitos, e dentre eles, eleições livres, justas e frequentes, que são traduzidas como a oportunidade igual e efetiva de votar e todos os votos serem contados como iguais, e encerra "não obstante, em discussões sobre diferentes sistemas de voto, pressupõe-se a necessidade de um sistema justo; a melhor maneira de obter a justiça e outros objetivos razoáveis é apenas uma questão de técnica" (DAHL, 2001, p. 99, 109-110).

É evidente, porém, que o processo eleitoral pode ser desvirtuado, de forma a produzir resultados que podem ser denominados como "antidemocráticos". Estou me referindo, aqui, ao processo eleitoral fraudulento e injusto, hipótese na qual o maquinário democrático é empregado não para proporcionar democracia, com a escolha legitima do líder, mas sim para legitimar um uma democracia fraudada, uma eleição aparente, acolher um líder já escolhido ou eliminar outro já preterido no sigilo de conspirações subversivas à democracia. De rigor, nesses casos, pode-se falar de eleição aparente, ${ }^{3}$ levando a um cenário de "democracia sem democracia", para me apropriar de expressão que toma o título da obra de Massimo Salvadori (2009), que se ocupa justamente do distanciamento entre os objetivos da democracia ideal e a realidade da democracia praticada (TAvARES, 2011, p. 5-16).

\subsection{Sistema eleitoral e corrupção}

A difícil missão de revelar a corrupção dificulta uma análise séria e realística do quanto o sistema eleitoral pode influenciar na sua disseminação ou con-

3. Encontram-se excluídas deste universo de referência, por óbvio, as não democracias, os Estados nos quais não há eleições para governantes, onde ditadores se perpetuam no Poder, lastreados na força física, na força religiosa ou em um regime de medo. 
tenção. Sobre o tema, Nicolau recorda que a Itália e o Japão ao passarem por escândalos na década de noventa migraram para os sistemas eleitorais mistos, tendo nesta ocasião, a Itália, abandonado o sistema de lista aberta (Nicolau, 2007 , p. 72). Recentemente, porém, a Itália enfrentou dissabores decorrentes dos resultados proporcionados pelo seu modelo, que só puderam ser sanados, em parte, por mecanismo externo ao modelo e absolutamente excepcional, a renúncia pessoal.

Os sistemas que possuem lista aberta tendem a ser mais vulneráveis ao clientelismo, já que os candidatos dependem da criação de vínculos cada vez mais próximos e firmes com seu eleitorado. "Como os deputados são incentivados a criar vínculos territoriais ou de identidade (religioso, profissional, corporativo) com os eleitores durante a campanha, eles precisam cultivar, ao longo do mandato, algum tipo de prestação de contas específico para essa 'clientela': emendas do orçamento; ação junto aos órgãos do Executivo federal ou estadual para implementar políticas que favoreçam as suas bases; apresentação de proposições legislativas".

"O incentivo do sistema de lista aberta para que os deputados eleitos cultivem uma relação estreita com clientelas específicas não significa que essa relação derivará necessariamente para a corrupção. Quanto às emendas do orçamento, há casos de corrupção (por exemplo, o escândalo do superfaturamento das ambulâncias), mas na grande maioria das situações, os deputados procuram garantir que verbas sejam liberadas para a realização de obras em suas bases eleitorais" (Nicolau, 2007, p. 73).

Embora não seja possível fazer uma relação direta entre corrupção e o modelo de sistema eleitoral, é evidente que dependendo do sistema adotado e de seus mecanismos ter-se-á maior ou menor facilidade para fiscalizar o uso e o abuso do poder econômico nas campanhas eleitorais.

Uma pesquisa do cientista político finlandês Lauri Karvonem realizou uma comparação do sistema eleitoral de 70 países, ocasião em que ficou determinada certa vulnerabilidade dos sistemas que adotam voto preferencial, como os casos de lista aberta ou flexível (Nicolau, 2007, p. 72-73).

Essa vulnerabilidade é fruto da dificuldade de fiscalização diante da pluralidade de candidatos, além do esforço para obter recursos que passa a ser realizado, geralmente, de maneira pessoal, individual. Esse tratamento individual tanto na obtenção dos recursos quanto na prestação de contas afasta o controle dos partidos, dificultando ainda mais a fiscalização pelo órgão competente.

Nicolau concorda com as dificuldades, realçando que o exemplo brasileiro combina "grandes distritos eleitorais, um grande número de candidatos e de 
partidos. Na eleição para deputado federal em 2002 concorreram 702 candidatos em São Paulo e 560 no Rio de Janeiro. Mesmo em um pequeno Estado como Alagoas, 75 nomes disputaram. É quase impossível examinar cuidadosamente as contas de tantos candidatos" (Nicolau, 2007, p. 73).

Portanto, embora não haja uma relação direta entre o sistema eleitoral e a amplificação ou diminuição da corrupção, os sistemas que adotam a lista aberta possuem dois fatores que, unidos, podem ter um efeito potencializador de perigosos. O primeiro se refere ao individualismo do candidato que geralmente dispõe-se pessoalmente a buscar recursos para a campanha, podendo gerar uma relação de dependência que transcenda a época da campanha; o outro fator é a pluralidade de candidatos, que efetivamente dificulta a fiscalização e atuação do órgão gestor, permitindo, inclusive, distinção de tratamento entre concorrentes, já que muitas vezes nem todos receberão o mesmo rigor na apreciação de suas contas e condutas.

\section{O SISTEMA ELEITORAL BRASILEIRO}

O sistema eleitoral brasileiro adota dois modelos distintos para as eleições, o majoritário e o proporcional. No sistema majoritário, elege-se o candidato mais votado. No proporcional, não será, necessariamente, o candidato mais votado que ascenderá à cadeira parlamentar. Nestes termos, a eleição de um candidato dependerá, igualmente, da votação obtida pela respectiva legenda partidária, quer dizer, pelo partido ao qual está filiado o candidato. Assim, embora a filiação partidária seja condição sine qua non para a elegibilidade, essa filiação poderá desempenhar um papel ainda mais relevante para o candidato do que a mera habilitação inicial para exercer o seu direito de concorrer a um cargo eletivo.

Elegem-se pelo sistema majoritário o Presidente da República, os Senadores, os Governadores e os Prefeitos Municipais. Portanto, tem-se, neste modelo, os chefes dos Executivos e parlamentares.

O sistema proporcional, por sua vez, regerá a eleição dos Deputados Federais, Estaduais e dos Vereadores.

Neste modelo proporcional, em síntese, a eleição de um determinado candidato será definida por dois elementos (quocientes), o quociente eleitoral (QE) e o quociente partidário (QP). O quociente eleitoral determina o número mínimo de votos necessários para que um dado partido político consiga eleger um candidato. E tal número é obtido por meio da divisão entre a quantidade total de votos válidos (excluídos os votos em branco e os nulos), obtidos em uma dada 
circunscrição eleitoral (que é a delimitação territorial para fins eleitorais), e o número total de cadeiras a serem preenchidas naquela circunscrição.

Ilustrativamente, valho-me da eleição para Deputado Federal. Nos termos do art. 45, caput, da CF/1988, a Câmara dos Deputados é composta por representantes do povo, eleitos em cada Estado-membro e no Distrito Federal. A Constituição estabelece um teto e um piso representativo para cada Estado-membro, com base em sua população (cf. art. 45, § 1. ${ }^{\circ}$, da CF/1988). Em outras palavras, o Estado mais populoso terá 70 cadeiras na Câmara dos Deputados e o menos populoso 8 cadeiras.

Uma vez definido, pelo TSE, a divisão de cadeiras entre os Estados-membros, e contabilizados o total de votos válidos, é possível alcançar o QE. Para elucidar, cito o exemplo do Estado de São Paulo, que por ser o Estado mais populoso do Brasil, tem direito a 70 cadeiras e obteve em uma eleição 20.789.076 votos. O quociente eleitoral portanto é de 296.987 votos (resultado da equação que divide o número de votos válidos pelas 70 cadeiras). Em outras palavras, cada partido deveria obter 296.987 votos para eleger um candidato.

O segundo elemento, que é o quociente partidário, por sua vez, representa o número de cadeiras que cada partido terá na Câmara dos Deputados, em face dos votos efetivamente obtidos. O resultado será obtido por meio da divisão do número total de votos auferidos pelo partido perante o quociente eleitoral, indicado acima. Imagine, assim, que um partido " $\mathrm{X}$ " tenha dois candidatos, Sr. Famoso e Sr. Ignorado. O partido "X" recebeu 600.000 votos, dos quais o Sr. Famoso obteve 599.999 votos e o Sr. Ignorado 1 voto apenas. De outra banda, o partido "Y" possui igualmente dois candidatos, sendo que o primeiro recebeu 250.000 votos e o segundo 50.000 votos.

No caso, serão eleitos ambos os candidatos do partido " $\mathrm{X}$ " e apenas um único candidato do partido "Y", ainda que um dos eleitos tenha recebido um único e solitário voto. Eis o âmago do sistema eletivo proporcional, que computa, prioritariamente, para fins de definição dos candidatos eleitos, o número total de votos percebidos pela legenda.

\subsection{Reforma política e sistema eleitoral: a proposta do distritão e o sistema proporcional}

Uma das propostas que na reforma política tomou conta do debate sobre eventual mudança do sistema eleitoral foi o denominado distritão, que consiste na mudança do sistema eleitoral proporcional para o majoritário nas eleições de deputados e vereadores. 
A questão foi debatida na mídia e nos corredores do Congresso Nacional, encontrando defensores e opositores de uma proposta dessa envergadura. $\mathrm{Na}$ Câmara dos Deputados, dentre os inúmeros eventos que trouxeram diversas autoridades no assunto, destaca-se o seminário realizado em 21.03 .2011 e, conforme o jornal O Globo, os cientistas políticos Renato Lessa e Jairo Nicolau teceram duras críticas ao modelo que segundo eles "representa um retrocesso democrático, ao enfraquecer os partidos e criar o hiperindividualismo na representação popular, com a eleição dos que têm mais recursos financeiros ou de personalidades".

Jairo Nicolau afirmou ainda que "atualmente, este tipo de eleição majoritária para deputados é adotado em apenas quatro países do mundo: Afeganistão, Jordânia, Vanuatu e Ilhas Pitcairn, no pacífico sul. No Japão, disse o professor, o sistema foi adotado de 1948 a 1993 e gerou clientelismo, corrupção e a total incapacidade de os partidos coordenarem a eleição. Segundo ele, levantamento feito entre 167 cientistas políticos no mundo considerou o distritão como o pior sistema eleitoral para o legislativo" (Disponível em: [http:// oglobo.globo.com/politica/cientistas-politicos-criticam-proposta-de-distritao-2807832\#ixzzlnp3qWfoj]. Acesso em: 27.02.2012).

$\mathrm{Na}$ busca de apoio para o modelo distrital ou mesmo do próprio distritão, seus defensores realçam a importância de ter eleitos aqueles que por si só mereceram votos. Entretanto, esta construção individualiza o sistema eleitoral, transformando o jogo político em jogo de pessoas, afastando os partidos políticos de suas precípuas funções.

Outra das grandes bandeiras utilizadas por aqueles que combatem o sistema proporcional é que em uma Democracia representativa resultaria em um grande número de partidos, ${ }^{4}$ muitos sem representatividade, atuando como verdadeiros partidos de aluguel.

Surge, aqui, a figura dos partidos nanicos e dos partidos de aluguel que elegem um número muito reduzido de representantes com atuação inexpressiva tanto diante da classe política quanto da própria sociedade. Muitos apontam a facilidade com que esses partidos passem a funcionar como um partido de aluguel, cuja finalidade, por exemplo, seria a de conceder a partidos maiores, mediante alguma sorte de retribuição, seu tempo no horário eleitoral gratuito e seu voto em importantes disputas políticas parlamentares.

O senso comum costumeiramente leva o observador menos atento a associar essa crítica à ausência de ideologia partidária por grande parte dos próprios

4. Em que pese o tema da governabilidade se entrelaçar com este ponto, ela não será considerada por estar fora dos objetivos deste estudo. 
partidos, mas como fiz em outra ocasião (TAVARES, 2011, p. 26-27), gostaria de discordar desta concepção, que visa, de certa forma, a enfraquecer a nossa Democracia representativa, reproduzindo brevemente os argumentos que já apresentei. O primeiro diz respeito à suposta ausência ideológica dos partidos.

Há, em sentido contrário, levantamento feito pelo Centro de Estudos Legislativos da Universidade Federal de Minas Gerais (UFMG), em projeto coordenado pela Universidade de Salamanca - Representação política e qualidade da democracia -, que demonstra a presença de aderência ideológica por grande parte dos partidos políticos. ${ }^{5}$ Os partidos políticos foram distribuídos em uma escala que visa a mensurar a ideologia partidária, entre partidos de esquerda e de direita. E consoante o resultado obtido, os partidos demonstrariam predileções claras em temas como maior ou menor intervenção do Estado na economia.

O segundo fato está em que mesmo partidos de menor representatividade desempenharam importante papel fiscalizatório, contribuindo decisivamente para o amadurecimento da democracia brasileira. Estou, aqui, fazendo menção a um dado recente, que envolve um partido que, em 2010, elegeu apenas 13 representantes no Congresso Nacional (12 na Câmara dos Deputados e 1 no Senado Federal). Trata-se do PPS. Referido Partido, em 03.02.2011, apresentou o PL 96/2001, que visa a dificultar a divulgação de pesquisas fraudulentas, demandando dos institutos de pesquisa um maior rigor na definição de seus critérios e na seleção do universo de pesquisados.

Em conclusão, multipartidarismo com partidos "nanicos" (o critério, aqui, é evidentemente quantitativo) não pode ser automaticamente identificado como um caminho para a fraude partidária (e deslegitimidade política) nestes partidos menores. O endereçamento da discussão sobre estes partidos e, de maneira geral, sobre o nosso sistema - discussão que pode e deve existir - deve ser outro.

\subsection{Reforma para facilitar a reforma}

Com a tomada dos trabalhos em 2012 na Câmara dos Deputados a retomada da reforma política é inevitável. Entretanto, o encerramento de 2011 foi marcado por um difícil impasse diante da acentuada divergência entre as lideranças partidárias, mais especificamente diante de dois eixos: o financiamento público de campanha e a mudança do sistema eleitoral.

5. Trata-se de estudo ainda não disponibilizado, mas que teve uma prévia de seus resultados publicados pelo jornal Valor Econômico, em matéria intitulada Nem tudo é o que parece. Caderno Eu \& Fim de Semana, 04.02.2011, p. 8-12. 
Em reportagem sobre o tema a revista Veja, sob o título "Parlamentares tentam desatar o nó da reforma política", a questão pôde ser sintetizada: "Os entraves poderiam ser resolvidos de forma simples: na disputa aberta. As propostas com mais votos passam, as outras são rejeitadas. Mas esse expediente, que constitui a essência do Parlamento, nem é cogitado. No presidencialismo à brasileira, o Congresso só avança nas propostas de interesse do governo". 6

O caminho para a solução pode ser mais curto e participativo, consoante notícia veiculada recentemente: "Diante das dificuldades para o Congresso chegar a um consenso sobre a reforma política, o deputado Miro Teixeira (PDT-RJ) diz que o caminho mais curto seria uma definição por parte do próprio eleitor. No fim do ano passado, ele apresentou projeto propondo um plebiscito em 2014, junto com as eleições presidenciais. Sua ideia é que o próprio eleitor defina que sistema considera mais adequado para a eleição de Deputados e Vereadores: se o proporcional, o distrital, o distrital misto, o distritão ou o voto em lista fechada. E propõe ainda consulta sobre o financiamento público de campanha". ${ }^{7}$

Entretanto, vale destacar que o "distritão" simplificaria a eleição, pois seriam eleitos os candidatos mais votados, independentemente do desempenho de seus partidos. Esse apelo proveniente da simplicidade desse sistema é preocupante quando se coloca uma questão de tamanha complexidade para a população decidir com um simples "sim" ou "não". Modelos como a já referida democracia deliberativa (dialógica) são contrários à mera participação como decisão, destacando a importância da discussão (diáologo) a partir dos "pontos de vista" relevantes para enfrentar-se o tema.

Essa é uma preocupação que também foi apresentada pelos cientistas políticos Renato Lessa e Jairo Nicolau: "A maior preocupação dos especialistas é quanto ao apelo fácil da proposta. Na opinião de Jairo Nicolau, hoje muitos acreditam que para o Congresso, as assembleias e para a Câmara são eleitos os que têm mais votos e o senso comum aprova tal ideia. Mas no sistema atual, há o quociente eleitoral que leva em conta o número de eleitos pelos partidos, não apenas a votação individual do candidato, fortalecendo os partidos. No sistema do distritão, todos concorrerão contra todos, prevalecendo o hiperindividualismo e agravando o problema de representação territorial, explica Jairo Nico-

6. Disponível em: [http://veja.abril.com.br/noticia/brasil/parlamentares-tentam-desatar-o-no-da-reforma-politica]. Acesso em: 27.02.2012.

7. Disponível em: [http://oglobo.globo.com/pais/miro-teixeira-propoe-plebiscito-sobre-reforma-politica-3719871\#ixzzlntFl4W2s]. Acesso em: 28.02.2012. 
lau. Em um estado, poderão ser eleitos apenas deputados de algumas regiões e muitos municípios poderão ficar sem qualquer representante". ${ }^{8}$

De fato, a facilidade de um processo plebiscitário entre sim ou não, e a suposta simplicidade de um novo modelo, podem mascarar o cerne da mudança e desviar a atenção das consequências implícitas no novo sistema, atraindo fraudulentamente os eleitores brasileiros. Nesses termos, a proposta de plebiscito pode ser uma reforma para facilitar outras reformas. Mas também se pode pensar em uma reforma para frear as reformas, o que passo a analisar abaixo.

\subsection{Outra reforma, para dificultar a reforma}

Dentre os diversos projetos de lei e de emendas constitucionais que tramitam sob o eixo da reforma política, tem-se a PEC 42, de 19.05.2011, que propõe a inserção de $\S 3 .^{\circ}$ ao art. 45 da $C F / 1988$, que passaria a dispor da seguinte maneira, sendo o texto em negrito o teor da PEC:

"Art. 45. A Câmara dos Deputados compõe-se de representantes do povo, eleitos, pelo sistema proporcional, em cada Estado, em cada Território e no Distrito Federal.

"§ 1. ${ }^{\circ}$ O número total de Deputados, bem como a representação por Estado e pelo Distrito Federal, será estabelecido por lei complementar, proporcionalmente à população, procedendo-se aos ajustes necessários, no ano anterior às eleições, para que nenhuma daquelas unidades da Federação tenha menos de oito ou mais de setenta Deputados.

"§ 2. ${ }^{\circ}$ Cada Território elegerá quatro Deputados.

"§ 3. ${ }^{\circ}$ A entrada em vigor de lei ou Emenda Constitucional que altere o sistema eleitoral estabelecido no caput deste artigo dependerá de aprovação em referendo."

Por meio dessa proposta cria-se um potente mecanismo de proteção do sistema eleitoral brasileiro, em sua vertente proporcional, além de trazer, obrigatoriamente, a sociedade brasileira, para decidir diretamente sobre a questão, agora por meio do uso mais racional e consciente do instituto do referendo.

É necessário, aqui, revisitar o conceito de referendo, distinguindo-o do plebiscito, sendo considerado, o primeiro, como a submissão, aos eleitores, de uma proposta normativa específica já aprovada, para que passe por seu crivo. Já o segundo, o plebiscito, é a submissão ao eleitorado de intenção legislativa

8. O Globo. Disponível em: [http://oglobo.globo.com/politica/cientistas-politicos-criticam-proposta-de-distritao-2807832\#ixzzlnp3qWfoj]. Acesso em: 27.02.2012. 
e, caso seja apoiada, sua transformação em norma. Portanto a diferença direta é referente ao momento de invocação e participação popular, mas a diferença indireta é o caminho legislativo adotado. Ou seja, em uma ocasião, submete-se à população uma norma pronta e acabada aguardando o referendo para sua vigência, em outra situação, consulta-se sobre a elaboração de norma a respeito.

No caso em questão, o referendo parece ser uma maneira ainda mais rígida de controle popular, já que dependeria de um projeto de norma que avançasse os obstáculos comuns conquistando a aprovação do número necessário de parlamentares e, vencida essa etapa legislativa oficial, seria ainda posta à sociedade para referendar ou não, e em caso negativo, todo aquele trabalho realizado seria descartado.

A questão é tão séria que a PEC 42/2011 entrou na primeira pauta para deliberação da reforma política no Senado. Sendo aprovada provocará, ao menos aparentemente, um efeito contrário ao que se noticia na grande mídia, de uma "reforma", pois se criará, na verdade, mais um obstáculo à transformação do sistema eleitoral.

\section{CONClusões}

O avanço democrático atrai a sociedade para uma maior participação na vida política, provocando manifestações em prol da ética e eficiência na classe política, trazendo a sociedade para searas que há pouco tempo pareciam blindadas, como ficou ilustrado pelo caso da Lei da Ficha Limpa, funcionando enfim, a sociedade, como um novo elemento para o regramento eleitoral.

Embora essa maior participação da sociedade seja desejável, em alguns casos, sua convocação pelo Congresso Nacional pode consistir em uma manobra que provocará entraves ou facilidades para a modificação de institutos consolidados, a ponto de facilitar uma virada radical de maneira experimental e perigosa diante do sistema eleitoral.

As reformas são de fato necessárias, em especial, a política que não despropositadamente é apelidada de mãe de todas as reformas. Entretanto, uma reforma não precisa dispensar a experiência realizada e mudar completamente o rumo de institutos consolidados, especialmente se a mudança sequer encontra respaldo em um debate amadurecido ou em necessidades experimentadas e transparentes em prol de outro modelo. A reforma pode servir também para dar sustentação, e neste caso, permanência e longa vida ao sistema eleitoral vigente, dificultando a distribuição de propostas casuísticas tendentes apenas a funcionar como uma pseudo resposta à sociedade diante de crise políticas sucessivas e de origem diversa. 
Como já se posicionou Fernando Limongi (2005, p. 31): "Sendo assim, o primeiro ponto a estabelecer é o que, quem quer que proponha reformas políticas deve estar consciente do terreno pantanoso em que se move, isto é, trata-se de um campo marcado pela incerteza. Este ponto deve ser frisado porque, da forma como o debate sobre reformas políticas tomou corpo no Brasil, tudo se passa como se toda e qualquer reforma sempre trouxesse benefícios. Se mudarmos, o resultado sempre será melhor do que o estado atual. Não necessariamente. Há outras duas possibilidades a considerar: as coisas podem piorar ou podem ficar como estão".

Em outra oportunidade me manifestei escrevendo que "Há, é certo, falhas em alguns pontos e pontos de vista diversos para alguns temas e institutos, mas que não justificam, experimentalismos inconsequentes. Uma guinada para um processo de alteração mais incremental depende, claramente, da conscientização dos pontos positivos e laudatórios do nosso sistema eleitoral e de nosso modelo representativo. Esta orientação depende, evidentemente, de um correto endereçamento dos problemas atuais" (TAVARES, 2011, p. 28).

A mudança consciente e qualitativa não pode ser e não está pressuposta na convocação popular de um simplório plebiscito. É preciso, aqui, um agir racional e coerente com nossa experiência democrática.

\section{REFERÊNCIAS BIBLIOGRÁFICAS}

Almeida, Alberto Carlos. Risco de dar um passo para trás. Valor Econômico. Caderno Eu \& Fim de Semana, 11.02.2011.

BraGA, Isabel. Cientistas políticos criticam a proposta de "distritão". O Globo, 21.03.2011. Disponível em: [http://oglobo.globo.com/politica/cientistas-politicos-criticam-proposta-de-distritao-2807832\#ixzzlnp3qWfoj]. Acesso em: 27.02.2012.

Castro, Gabriel. Parlamentares tentam desatar o nó da reforma política. Veja, 22.02.2012. Disponível em: [http://veja.abril.com.br/noticia/brasil/parlamentares-tentam-desatar-o-no-da-reforma-politica] . Acesso em: 27.02.2012.

DAhL, Robert A. Sobre a democracia. reimp. Trad. Beatriz Sidou. Brasília: UnB, 2009 .

Fisichella, Domenico. Elezioni e democrazia: un'a analisi comparata. Bologna: Il Mulino, 2008.

Limongi, Fernando. Reforma política no Brasil. Cadernos Fórum Nacional. n. 1. p. 31. Rio de Janeiro: Inae, jun. 2005. Disponível em: [www.inae.org.br]. Acesso em: 12.04.2011.

Nicolau, Jairo Marconi. Sistemas eleitorais. 5. ed. rev. e atual. Rio de Janeiro: FGV, 2004. 
. Cinco opções, uma escolha. O debate sobre a reforma do sistema eleitoral no Brasil. Plenarium. n. 4. Brasília: Câmara dos Deputados, maio de 2007. Disponível em: [http://jaironicolau.iesp.uerj.br/artigos/plenarium_04.pdf].

Salvadori, Massimo L. Democrazie senza democrazia. Roma-Bari: Laterza, 2009.

SELL, Carlos Eduardo. Introdução à sociologia política: política e sociedade na modernidade tardia. Petrópolis: Vozes, 2006.

Tavares, André Ramos. Curso de direito constitucional. 10. ed. São Paulo: Saraiva, 2012.

. Processo eleitoral e democracia: a delicada e necessária contextualização da reforma política no Brasil. Revista de Estudos Eleitorais. vol. 6. n. 1. p. 9-30. Brasília: EJE-TSE, jan.-abr. 2011.

Torres, Izabelle. A velha tentativa de votar a reforma política. Correio Braziliense, 05.05.2009. Disponível em: [www.correiobraziliense.com.br]. Acesso em: 25.02.2012.

VAsConcelos, Adriana. Miro Teixeira propõe plebiscito sobre reforma política. $O$ Globo, 19.01.2012. Disponível em: [http://oglobo.globo.com/pais/miro-teixeira-propoe-plebiscito-sobre-reforma-politica-3719871\#ixzz1ntFl4W2s]. Acesso em: 28.02.2012.

\section{Pesquisas do Editorial}

\section{Veja também Doutrina}

- A inexistência de um sistema eleitoral misto e suas conseqüências na adoção do sistema alemão no Brasil, de Luís Virgílio Afonso da Silva - RDCl 23/238;

- A reforma política, de Michel Temer - RIASP28/437; e

- Direito eleitoral, de Miguel Reale - RDCl 18/32. 